\title{
Varicella-zoster virus CNS vasculitis and RNA polymerase III gene mutation in identical twins
}

Madalina E. Carter-Timofte, MRes, * Anders F. Hansen, ${ }^{*}$ Maibritt Mardahl, PhD, Sébastien Fribourg, PhD, Franck Rapaport, PhD, Shen-Ying Zhang, MD, PhD, Jean-Laurent Casanova, MD, PhD, Søren R. Paludan, PhD, DMSc, Mette Christiansen, PhD, Carsten S. Larsen, MD, DMSc, and Trine H. Mogensen, MD, PhD, DMSc

Neurol Neuroimmunol Neuroinflamm 2018;5:e500. doi:10.1212/NXI.0000000000000500

\section{Abstract}

\section{Objective}

Deficiency in the cytosolic DNA sensor RNA Polymerase III (POL III) was recently described in children with severe varicella-zoster virus (VZV) infection in the CNS or lungs. Here, we describe a pair of monozygotic female twins, who both experienced severe recurrent CNS vasculitis caused by VZV reactivation. The clinical presentation and findings included recurrent episodes of headache, dizziness, and neurologic deficits, CSF with pleocytosis and intrathecal VZV antibody production, and MRI of the brain showing ischemic lesions.

\section{Methods}

We performed whole-exome sequencing and identified a rare mutation in the POL III subunit POLR3F. Subsequently, antiviral responses in patient peripheral blood mononuclear cells (PBMCs) were examined and compared with healthy controls.

\section{Results}

The identified R50W POLR3F mutation is predicted by bioinformatics to be damaging, and when tested in functional assays, patient PBMCs exhibited impaired antiviral and inflammatory responses to the POL III agonist poly $(\mathrm{dA}: \mathrm{dT})$ and increased viral replication compared with controls.

\section{Conclusions}

Altogether, these cases add genetic and immunologic evidence to the novel association between defects in sensing of AT-rich DNA present in the VZV genome and increased susceptibility to severe manifestations of VZV infection in the CNS in humans.

\author{
Correspondence \\ Dr. Mogensen \\ trinmoge@rm.dk
}

\section{RELATED ARTICLE}

Preprints and the implications for subsequent peer review and publishing

\footnotetext{
*These authors contributed equally.
}

From the Departments of Infectious Diseases (M.E.C-T., A.F.H., M.M., C.S.L., T.H.M), Clinical Immunology (M.C.), and Clinical Medicine (T.H.M), Aarhus University Hospital, Denmark; Université de Bordeaux (S.F.), INSERM U1212, CNRS 5320, France; St.Giles Laboratory of Human Genetics of Infectious Diseases (F.R., S.-Y.Z., J.-L.C.), Rockefeller Branch, the Rockefeller University, New York, NY; Laboratory of Human Genetics of Infectious Diseases (S.-Y.Z., J.-L.C.), Necker Branch, INSERM UMR 1163; Paris Descartes University (S.-Y.Z, J.-L.C.), Imagine Institute, France; and Department of Biomedicine (M.E.C-T., S.R.P., T.H.M.), Aarhus University (AU)

Funding information and disclosures are provided at the end of the article. Full disclosure form information provided by the authors is available with the full text of this article at Neurology.org/NN. 


\section{Glossary}

CADD = combined annotation dependent depletion; DOCK = dedicator of cytokinesis; IFN = interferon; PBMC = peripheral blood mononuclear cell; POL III = polymerase III; VZV = varicella-zoster virus; WES = whole-exome sequencing.

Varicella-zoster virus (VZV) is a human pathogenic alphaherpesvirus causing chickenpox in children during primary infection and herpes zoster in elderly or immunocompromised individuals on reactivation from latency. However, in a minority of infected individuals, VZV may cause pneumonia, or even more rarely, infection in the CNS. VZV disease manifestations in the CNS may present as a viral meningoencephalitis with classic signs of viral meningitis but may also present in a more atypical stroke-like manner, in which case, the immunopathogenesis appears to be vasculitis. ${ }^{1}$ VZV vasculitis can occur during primary infection or during reactivation from latency, and in both cases with considerable delay, and may affect either small or large vessels of the cerebral parenchyma. Whereas large-vessel disease is most common in immunocompetent individuals, small-vessel disease usually develops in immunocompromised patients; however, in some patients, both large and small vessels are involved. Overall, CNS involvement in VZV infection, of which CNS vasculitis represents only a smaller fraction, is rarer with an estimated incidence of 1-3/ 10.000 primary VZV infections, whereas the incidence of meningoencephalitis during VZV reactivation is more difficult to establish. ${ }^{2,3}$

Here, we describe 2 monozygotic twins with similar clinical presentations, suggesting recurrent $\mathrm{CNS}$ vasculitis caused by VZV reactivation. Genetic and functional immunologic analyses were performed to examine a possible genetic and pathophysiologic basis of the clinical phenotype.

\section{Methods}

\section{Patient material}

The patient and her twin sister were admitted for clinical immunologic evaluation. See supplementary medical history for further clinical details. A total of $84 \mathrm{~mL}$ of blood was drawn from each patient. Four milliliters of blood was used for DNAisolation and subsequent whole-exome sequencing (WES), whereas the remaining $80 \mathrm{~mL}$ was used for isolation of peripheral blood mononuclear cells (PBMCs), performed using SepMate tubes (Stemcell Technologies, Vancouver, BC, Canada) with Ficoll-Paque (GE Healthcare Life Sciences, Chicago, IL), and cells were then stored in liquid nitrogen. Control PBMCs were obtained from healthy controls after written consent.

\section{Whole-exome sequencing}

DNA was isolated from ethylenediaminetetraacetic acid (EDTA)-stabilized blood using EZ1 DNA Blood $350 \mu \mathrm{L}$ Kit and an EZ1 Advanced XL instrument (Qiagen, Hilden, Germany) according to the manufacturer's instructions. See supplementary methods for description of WES data analysis.

\section{Stimulation of PBMCs}

PBMCs from patients and controls were thawed in 50-mL tubes containing $15 \mathrm{~mL}$ of preheated media (RPMI-1,640 w/Lglutamin [Biowest, Riverside, MO]) supplemented with $10 \%$ heat-inactivated fetal bovine serum (Biowest) and $1 \%$ penicillin/ streptomycin and spun down at $350 \mathrm{~g}$ for 8 minutes. The PBMCs were resuspended in media and divided into 24-well plates at a concentration of $5 \times 10^{5}$ cells per $300 \mu \mathrm{L}$ media per well. Next, cells were incubated overnight at $37^{\circ} \mathrm{C}$ in an atmosphere of $5 \% \mathrm{CO}_{2}$. The cells were subsequently transfected using Lipofectamine 3000 at $0.75 \mu \mathrm{L} / \mu \mathrm{g}$ DNA (Invitrogen by Thermo Fischer Scientific, Waltham, MA) and Opti-MEM (Gibco, by Life Technologies, Carlsbad, CA), by the TLR3-agonist Poly(I:C) $[2 \mu \mathrm{g} / \mathrm{mL}]$ or transfected with the POL III agonist poly(dA:dT) $[2 \mu \mathrm{g} / \mathrm{mL}$ ] [Cayla, Invivogen, San Diego, CA]). Cells were incubated for 6 hours before harvest and cell lysis. For virus experiments, PBMCs were infected with VZV-infected MeWo cells (ROka strain) (PBMC:MeWo-VZV ratio, 1:1). One vial of VZV-infected MeWo cells was thawed, spun down at $1,000 \mathrm{rpm}$ for 10 minutes, and resuspended in $400 \mu \mathrm{L}$ preheated media. From this solution, $30 \mu \mathrm{L}$ was added to the wells to be stimulated with VZV. Cells were incubated for 6 hours, except VZV, which was incubated with PBMCs for 48 hours before cells lysis and RNA harvest. The stimulations were performed in triplicates, and each experiment was performed 2-3 times.

\section{Isolation of RNA and reverse transcription quantitative PCR}

RNA was purified from PBMC whole-cell lysates, as per the manufacturer's instructions, using the High Pure RNA Isolation Kit (Roche, Basel, Switzerland). Before cDNA synthesis, VZVinfected PBMCs underwent DNAse treatment and removal step (Turbo-DNA-free Kit, Thermo Fischer Scientific, Watlham, MA). From the isolated RNA, cDNA was synthesized using the QuantiTect Reverse Transcription Kit (Qiagen, Hilden, Germany) following the manufacturer's instructions. The synthesized cDNA was subsequently used for real-time quantitative PCR using TaqMan probes, allowing amplification and analysis of levels of IFNB1, TNFA, the interferon (IFN)stimulated gene CXCL10, and the viral VZV gene ORF63. TBP was used as housekeeper gene for reference. All analyses were performed as technical duplicates for all samples, and the TaqMan probes (Thermo Fischer Scientific, Waltham, MA) used were IFNB1: Hs01077958; TNFA: Hs01113624; and CXCL10: Hs01124251. For analysis of ORF63, which was performed separately, SYBR Green was used for ORF63 (LGC Biosearch Technologies, Petaluma, CA).

\section{Statistical analysis}

The Mann-Whitney rank-sum $t$-test was used to determine statistical significance; nonsignificant $(\mathrm{ns}) ;{ }^{*} p \leq 0.05 ;^{* *} p \leq 0.001$. 


\section{Ethics}

The project was approved by the Regional Ethics Committee (\#1-10-72-275-15), and the patients provided informed written consent before blood sampling.

\section{Data availability}

All data published may be shared at the request of other investigators.

\section{Results}

A 37-year-old woman (P1) was referred to the international center for immunodeficiency diseases for clinical immunologic evaluation based on recurrent stroke-like manifestations diagnosed in the neurologic department as presumed CNS vasculitis caused by VZV reactivation. The first episode occurred at age 25 years when she experienced an episode of left-sided hemiparesis and headache. CT of the brain demonstrated two infarcts in the right temporal region and 2 minor ones in the cerebellum. Eight years later, she was readmitted with right-sided hemiparesis, and -paresthesias double vision and impaired balance, and $\mathrm{CT}$ again revealed a 4-mm infarction. Neurologic symptoms including headache, dizziness, and paresthesias of the left arm and leg developed 1 year later, leading to another hospital admission. MRI demonstrated a lacunar infarction in the right subcortical temporal region. A subsequent lumbar puncture revealed mild pleocytosis of $7 \times 10^{9}$ cells/L and an elevated index for intrathecal VZV IgG antibodies with negative intrathecal herpes simplex virus (HSV) index, negative PCR for HSV-1/2, VZV, and enterovirus and negative bacterial cultures from the CSF (table 1). Sarcoidosis, MS, and systemic vasculitis were excluded by blood tests, MRI, and angiography, respectively. The patient was treated with acyclovir $10 \mathrm{mg} / \mathrm{kg}$ tds for 14 days together with corticosteroids (prednisolone $50 \mathrm{mg}$ once daily for 10 days) because the clinical presentation was interpreted as CNS vasculitis.

The identical twin sister (P2) experienced a very similar medical history with the first episode at the age of 35 years, including right-sided paresthesias followed after 6 months by another episode of right-sided paresthesias involving upper and lower extremities and the face. Lumbar puncture demonstrated a mild pleocytosis of $10 \times 10^{9}$ cells $/ \mathrm{L}$ and positive intrathecal test for VZV, although no virus, neither HSV-1/2 nor VZV was detected by PCR. MRI of the total medulla and brain demonstrated myelitis at the level of $\mathrm{C} 6$ and Th2 (figure 1A) and signs of paraventricular parietal cerebral ischemic lesions on the left side with several small juxtacortical lesions bilaterally (figure 1, B and C). Another episode occurred 6 months later with reoccurrence of VZV intrathecal IgG antibodies (positive VZV IgG index in CSF) leading to a presumed diagnosis of VZV vasculitis. Finally, both sisters were reported to have had a normal course of primary VZV infection (chickenpox) in childhood at almost the same time. Moreover, they did not report any increased susceptibility to other viral, bacterial, or fungal infections, neither in the past 

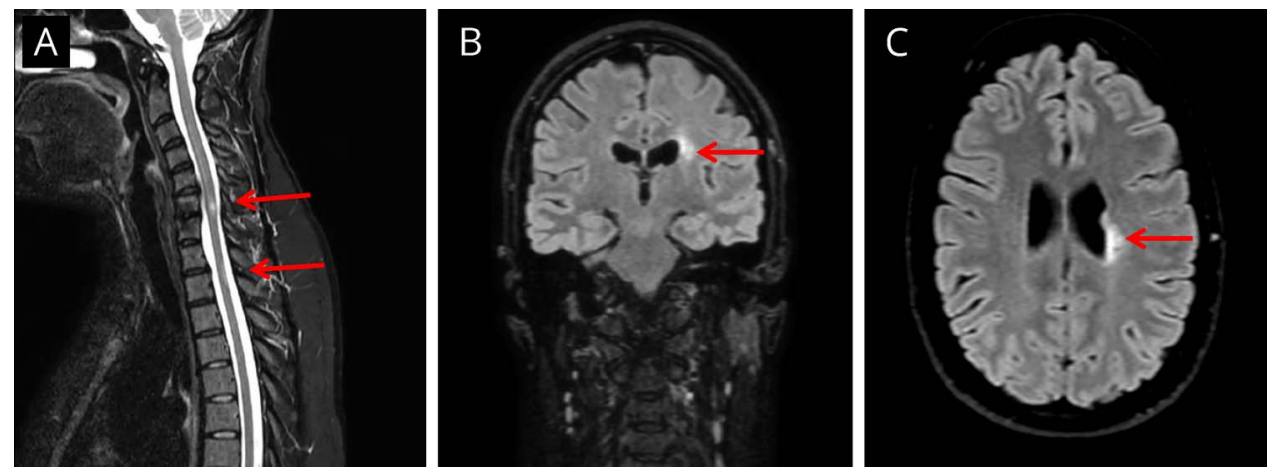

(A) MRI of the medulla (sagittal STIR sequence) demonstrating ischemic lesions/myelitis at the level of $C 6$ and Th2. (B and C) MRI of the brain (3D FLAIR sequence) in (B) coronal and (C) transverse projection demonstrating a parietal paraventricular lesion on the left side. Red arrows indicate lesions in the medulla and brain.

nor at present. According to Danish health recommendations, neither of the sisters were vaccinated against VZV.

Because of this unusual presentation in both monozygotic twin sisters, we suspected a genetic etiology of the recurrent VZV CNS vasculitis. A routine clinical immunologic evaluation was normal, including normal immunoglobulins, lymphocyte distribution and proliferation within the normal range, and a negative HIV test. We therefore performed WES on DNA from $P 1$, which resulted in the identification of a novel missense mutation in the POLR3F subunit of the cytosolic DNA sensor RNA Polymerase III (POL III) (figure 2A). The mutation, R50W POLR3F, is rare and predicted to be damaging by bioinformatics software, such as PolyPhen-2 and SIFT and with a high combined annotation dependent depletion (CADD) score of 25.8, which is well above the mutation significance cutoff score of 13.0 for this gene. ${ }^{4,5}$ Further population genetic analyses, based on study of POLR3F variations from the GnomAD database, demonstrate a lower frequency of nonsynonymous and loss-of-function mutations with a CADD score $>12$, and a global minor allele frequency $<10^{-4}$ for nonsense mutations. Moreover, when performing natural selection assessment based on mouse and human gene homologous comparison, the POLR3F gene appears to be under purifying selection as reflected by a $\mathrm{dN} / \mathrm{dS}$ score of 0.0172 below the threshold of 1 . Finally, there is a selective pressure neutrality index of 0.126 , predicting moderate purifying selection (figure 2A and figure e-1, links.lww.com/NXI/A73).

Figure 2 Identification of a heterozygous mutation in $P O L R 3 F$, protein structure, and pedigree

A

\begin{tabular}{ll}
\hline Genetic information & P1 and P2 \\
\hline Gene ID & 10621 \\
Transcript ID & NM_006446.3 \\
Transcript variant & c.148C $>$ T \\
Protein variant & p.R50W \\
CADD score & 25.8 \\
MSC & 13.0 \\
GDI score & 61.743 \\
Selective pressure NI & 0.126 \\
dN/dS & 0.017 \\
ExAc frequency & 0.000 \\
GnomAD frequency & $0.000 / 0.000$ \\
Zygosity & Heterozygous \\
\hline
\end{tabular}

C

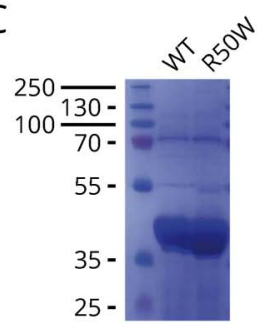

B

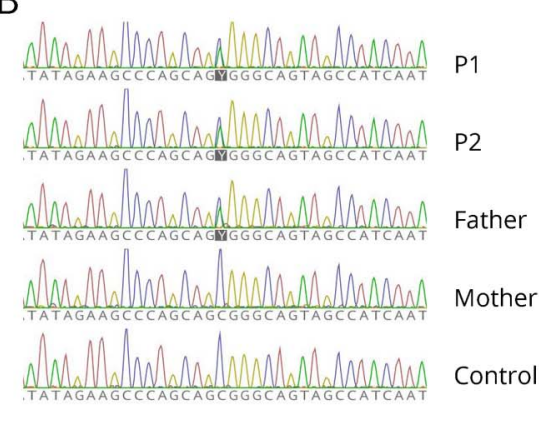

E

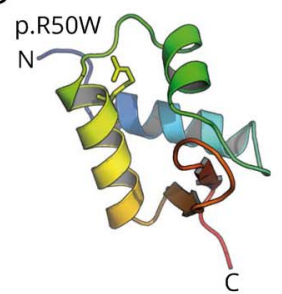

(A) Summary of genetic information on the identified variant in POLR3F. (B) Sanger sequencing of $\mathrm{P} 1, \mathrm{P} 2$, their parents, and a control, with the $P O L R 3 F$ variant c. $148 \mathrm{C}>\mathrm{T}$ present in P1, P2, and the father. (C) Coomassie blue staining of SDS-PAGE revealing similar solubility of wild-type POLR3F and mutant R50W POLR3F expressed from Escherichia coli. (D) Molecular model of POLR3F first winged helix domain based on the Protein Data Bank ID 2DK8 with the R50 shown as sticks. (E) Pedigree showing the affected monozygotic twins with the R50W $P O L R 3$ F variant inherited in a heterozygous manner from the father with possible previous VZV CNS disease. CADD = combined annotation dependent depletion; $\mathrm{dN} / \mathrm{dS}=$ ratio of non-synonymous to synonymous substitutions; GDI = gene damage index; $\mathrm{MSC}=$ mutation significance cutoff; $\mathrm{NI}=$ neutrality index. 
The identified POLR3F variant (NM_001282526.1 c.25C $>$ T, p.R50W) causes an amino acid shift from the positively charged arginine (R) to a bulky aromatic tryptophan (W) in the $\mathrm{N}$-terminal region of the POLR3F subunit, which together with POLR3C and POLR3G constitutes a POLR3 subcomplex essential for POLR3 promoter transcription initiation(figure 2, A and D). As expected, the same POLR3F variant was found by Sanger sequencing to be present in the monozygotic twin sister. The mutation was inherited from the father (figure $2 \mathrm{~B}$ ), who was previously admitted to hospital with clinical signs and symptoms of stroke, which retrospectively might have been linked to VZV CNS vasculitis; however, this was not examined at the time. Biochemical analyses demonstrated that expression and solubility of the mutant POLR3F protein were unaltered compared with wild type, suggesting that the R50W mutation affects protein function, such as ligand recognition or enzymatic conversion of the adenosine-thymidine-rich DNA ligand into $5^{\prime}$ triphosphorylated RNA, rather than expression of the POLR3F protein (figure 2C). Two additional rare gene variants with a high CADD score identified through the WES analysis are listed in table e-2 (links.lww.com/NXI/A74); however, none of these were judged to be of any relevance for the infectious phenotype of these patients.

Next, we investigated in vitro antiviral and inflammatory responses in P1 to VZV infection and the POL III agonist poly (dA: $\mathrm{dT})$, the latter being a constituent of the AT-rich VZV genome (figure 3). As shown, PBMCs from P1 showed significantly impaired IFN $\beta-$, TNF $\alpha-$, and CXCL10 responses to poly(dA:dT) (figure 3, A-C). By contrast, responses to transfected Poly(I:C) were normal as expected because this ligand activates the cytosolic RNA receptor Retinoic acidinducible-I (RIG-I) directly downstream of POL III (figure 3, D-F). Moreover, we observed significantly impaired production of the 2 proinflammatory cytokines TNF $\alpha$ and IL6 in response to VZV infection of PBMCs from P1 and controls (figure 3, J and $\mathrm{K}$ ), although $\operatorname{IFN} \beta, \operatorname{IFN} \lambda$, and CXCL10 responses were comparable between $\mathrm{P} 1$ and controls (figure 3, G-I). It is important to note that on VZV infection, a significantly increased amount of the viral immediate-early gene ORF63 mRNA was detected in P1 cells relative to controls, demonstrating increased viral replication, i.e., reduced viral control in patient cells (figure 3L). Taken together, these results demonstrate impaired immune responses to the POL III ligand poly (dA:dT) and impaired proinflammatory responses to VZV in the setting of increased VZV replication in patient cells.

\section{Discussion}

A number of primary immunodeficiencies affecting innate and adaptive immunity have been previously recognized to predispose to severe disseminated VZV infection. These classically comprise disseminated VZV infection occurring in children with severe combined immunodeficiency, as well as immunodeficiencies more specifically involving defects in natural killer cells, including MonoMAC caused by the GATA2 mutation, but also involves a number of immunodeficiencies, in which the precise cellular and immunologic basis of increased susceptibility to VZV infection is less well defined. These include autosomal recessive hyper-IgE syndrome caused by a mutation in dedicator of cytokinesis 8 (DOCK8) or TYK2, mendelian susceptibility to mycobacterial disease due to interferon gamma receptor 1 deficiency, and, finally, DOCK2 deficiency. ${ }^{6}$

Recently, a novel primary immunodeficiency involving POL III deficiency in 4 children with severe VZV infection in the CNS and/or lungs was described. ${ }^{7}$ In the present work, we provide further genetic and immunologic evidence for a role of POL III in protective immunity to VZV infection, particularly in the CNS. RNA POL III is a 17-subunit enzyme with dual functions in both promoter-dependent transcription of tRNA and rRNA and innate sensing of AT-rich DNA, converting this into 5'-phosphorylated single-stranded RNA, which serves as a ligand for the RNA sensor RIG-I. ${ }^{8,9}$ The present report is the first description of an association between the POLR3F subunit of POL III and severe recurrent VZV CNS vasculitis. There has been a report of the presence of a potentially disease-causing mutant in Toll-like receptor (TLR) 3 in a 31-year-old male patient with VZV meningoencephalitis, although no functional studies to support a role for TLR3 deficiency in VZV CNS infection were provided. ${ }^{10}$ Of note, mutations in the POLR3A and POLR3B subunits have been genetically linked to noninfectious hypomyelinating leukodystrophy. ${ }^{11,12}$

The cases described here are notable for the occurrence of an extremely rare disease presentation suggestive of CNS vasculitis caused by recurrent VZV reactivation in monozygotic twins. The clinical history consisting of recurrent neurologic deficits presenting in a stroke-like manner with headache, hemiparesis, pleocytosis, and elevated VZV IgG levels in CSF and white matter lesions detected on brain MRI are all in agreement with VZV vasculitis in the CNS. However, this diagnosis is rather difficult to make with certainty, and even MR angiography is only suggestive and not a conclusive evidence of this diagnosis. Moreover, histopathologic evidence of vasculitis in the CNS could not be provided in the 2 cases described here. In a case series of 14 adults with cerebral vasculitis, it was reported that positive intrathecal anti-VZV IgG combined with relevant neurologic symptoms and imaging was a definite marker of this disease rather than VZV DNA detection by PCR because the latter was positive in only 4 of the patients. ${ }^{13}$ In this respect, the absence of detectable VZV by PCR in CSF is not surprising and is consistent with VZV CNS meningoencephalitis, including vasculitis. ${ }^{2}$ It is important to note that both patients described in the present study have a good clinical response to acyclovir and corticosteroid treatment during clinical episodes but experience recurrence of symptoms and new MRI lesions during discontinuation of acyclovir. There is clearly a different pathogenesis between classic VZV meningoencephalitis and the presence of vasculitis developing in some cases of VZV CNS infection. ${ }^{1}$ At the cellular level, increased viral replication, which for VZV is known to also 
Figure 3 Impaired antiviral and inflammatory responses to the POL III ligand poly(dA:dT) and increased VZV replication in patient PBMCs

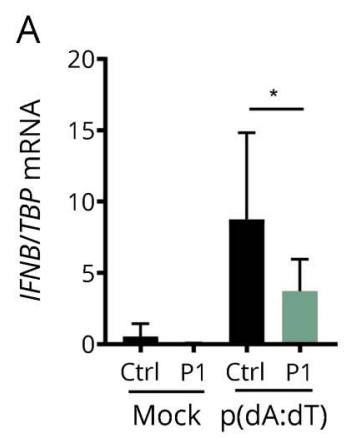

D

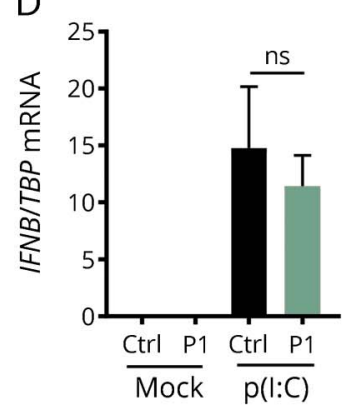

G
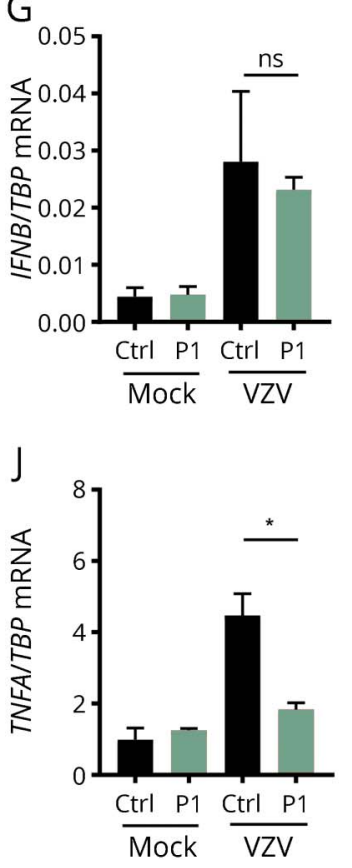

B

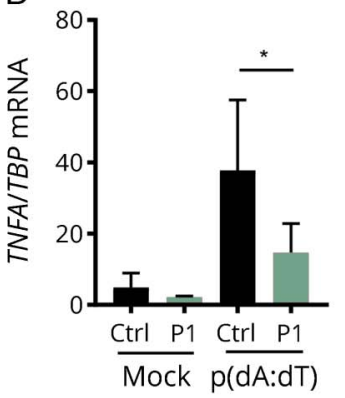

E

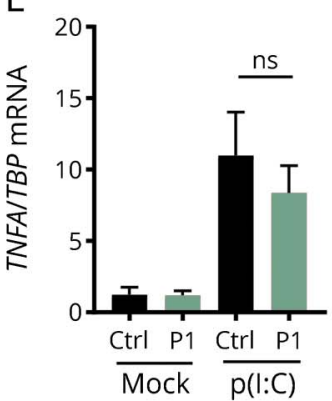

$\mathrm{H}$

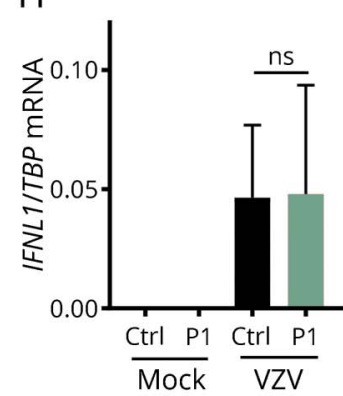

K

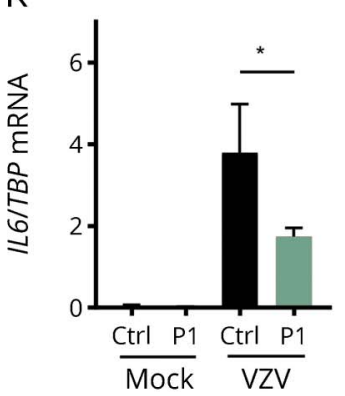

C

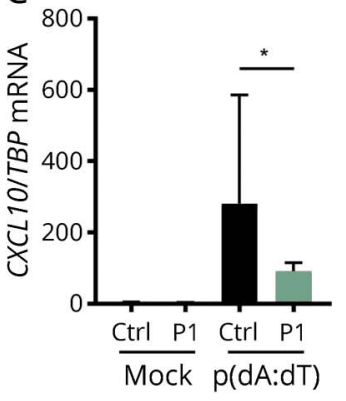

F

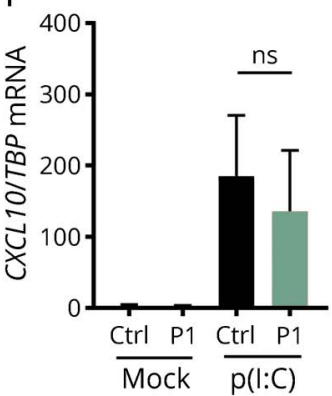

1

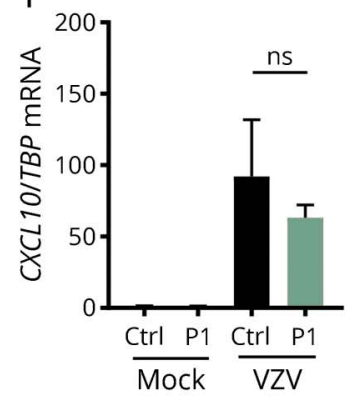

L

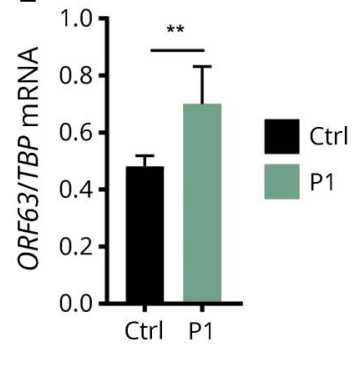

PBMCs from $\mathrm{P} 1$ and 9 healthy controls were used for experiments. (A-C) PBMCs were transfected with poly(dA:dT) $(2 \mu \mathrm{g} / \mathrm{mL})$ for 6 hours. (D-F) PBMCs were transfected with poly(l:C) $(2 \mu \mathrm{g} / \mathrm{mL})$ for 6 hours. (G-K) VZV-infected MeWo cells were cocultured with PBMCs for 48 hours. Total RNA was isolated for measurement of mRNA for the indicated cytokines by reverse transcription-qPCR. (L), VZV replication was assessed by measuring the viral transcript ORF63. Cytokine levels and ORF63 levels were normalized to TBP and compared with pooled results of 9 healthy controls. Data are shown as column bars, and error bars represent SD. The nonparametric Mann-Whitney ranksum test was used to evaluate statistical significance between groups. Significance level $\star_{p}<0.05$ and ${ }^{*} p<<$ 0.001. $\mathrm{mRNA}=$ messenger RNA; $\mathrm{PBMC}=$ peripheral blood mononuclear cell. include endothelial cells within the CNS, may evoke enhanced inflammatory responses secondary to the presence of virus and thereby explain the occurrence of vasculitis and immunopathology in these patients ${ }^{1}$.

In summary, we describe 2 female monozygotic twins both experiencing recurrent stroke-like episodes associated with VZV reactivation in the CSF diagnosed as presumed CNS vasculitis, in whom we identified a heterozygous missense mutation in the POLR3F subunit of the cytosolic DNA sensor
POL III, resulting in impaired antiviral responses and increased VZV replication in patient PBMCs compared with controls. Since then, both $\mathrm{P} 1$ and $\mathrm{P} 2$ receive prophylactic acyclovir treatment, and notably, P1 has repeatedly experienced symptoms and new white matter lesions when interrupting prophylaxis. We propose that impaired sensing of AT-rich DNA in the VZV genome contributes to increased susceptibility to the rare condition of VZV-induced CNS vasculitis, thereby extending the spectrum of CNS manifestations linked to POL III deficiency. Altogether, this case adds 
further genetic and immunologic evidence to the novel association between defects in DNA sensing and increased susceptibility to severe manifestations of VZV infection in the CNS in humans.

\section{Author contributions}

T.H. Mogensen, C.S. Larsen, and J.-L. Casanova conceived the idea. T.H. Mogensen and C.S. Larsen identified the patients. M.E. Carter-Timofte, A.F. Hansen, and S. Fribourg performed experiments. MCT, A.F. Hansen, M. Mardahl, F. Rapaport, S.Y.Zhang, T.H. Mongensen, S.R. Paludan, and M. Christiansen analyzed data. T.H. Mogensen wrote the first version of the manuscript. All authors read and approved the final version of the manuscript.

\section{Acknowledgment}

The authors thank all patients involved in this study. T.H. Mogensen is funded by The Independent Research Fund Denmark (4004-00047B) and Aarhus University Research Fund (AUFF-E-2015-FLS-66). A.F. Hansen received funding from the Faculty of Health, Aarhus University. The Ph.D. scholarship to MCT is funded by the European Union under the Horizon 2020 research and innovation program (H2020) and Marie Skłodowska-Curie Actions-Innovative Training Networks Programme MSCA-ITN GA 675278 EDGE (Training Network providing cutting-EDGE knowlEDGE on Herpes Virology and Immunology). S. Fribourg is funded by INSERM. Finally the authors thank consultant Anette Loft Edal from the Department of Radiology, University Hospital Lillebælt, Kolding, Denmark, for preparing the MR images.

\section{Study funding}

No targeted funding reported.

\section{Disclosure}

M.E. Carter-Timofte, A.F. Hansen, M. Mardahl, and S. Fribourg report no disclosures. F. Rapaport received research support from Shapiro-Silverberg Fund for the Advancement of Translational Research. S.-Y. Zhang served on the editorial board of Frontiers in Immunology. J.-L. Casanova served as editor of Proceedings of the National Academy of Sciences of the United States of America, Journal of Experimental Medicine, Current Opinion in Pediatrics, Current Opinion in Immunology, and Journal of Medical Genetics; served as Deputy Editor-inChief for Clinical Immunology; served as an editorial board member of Philosophical Transactions of the Royal Society; consulted for Genentech, Nimbus, Vitae, Sanofi, and Pfizer; and received research support from Biogen Idec, NIH/ DHHS/National Vaccine Program Office, Howard Hughes Medical Institute, and Qatar National Research Fund. S.R. Paludan and M. Christiansen report no disclosures. C.S. Larsen served on the editorial board of Travel Medicine and Infectious Diseases. T.H. Mogensen reports no disclosures. Full disclosure form information provided by the authors is available with the full text of this article at Neurology. org/NN.

\section{Publication history}

Previously published at bioRxiv doi: 10.1101/244848. Received by Neurology: Neuroimmunology \& Neuroinflammation April 18, 2018. Accepted in final form July 18, 2018.

\section{References}

1. Gilden D, Cohrs RJ, Mahalingam R, Nagel MA. Varicella zoster virus vasculopathies: diverse clinical manifestations, laboratory features, pathogenesis, and treatment. Lancet Neurol 2009;8:731-740.

2. Gilden DH, Mahalingam R, Cohrs RJ, Kleinschmidt-DeMasters BK, Forghani B. The protean manifestations of varicella-zoster virus vasculopathy. J Neurovirol 2002; 8(suppl 2):75-79.

3. Gershon AA, Breuer J, Cohen JI, et al. Varicella zoster virus infection. Nat Rev Dis Primers 2015;1:15016.

4. Kircher M, Witten DM, Jain P, O'Roak BJ, Cooper GM, Shendure J. A general framework for estimating the relative pathogenicity of human genetic variants. Nat Genet 2014;46:310-315.

5. Itan Y, Shang L, Boisson B, et al. The mutation significance cutoff: gene-level thresholds for variant predictions. Nat Methods 2016;13:109-110.

6. Duncan CJ, Hambleton S. Varicella zoster virus immunity: a primer. J Infect 2015; 71(suppl 1):S47-S53.

7. Ogunjimi B, Zhang SY, Sorensen KB, et al. Inborn errors in RNA polymerase III underlie severe varicella zoster virus infections. J Clin Invest 2017;127: 3543-3556.

8. Ablasser A, Bauernfeind F, Hartmann G, Latz E, Fitzgerald KA, Hornung V. RIG-Idependent sensing of poly(dA:dT) through the induction of an RNA polymerase IIItranscribed RNA intermediate. Nat Immunol 2009;10:1065-1072.

9. Chiu YH, Macmillan JB, Chen ZJ. RNA polymerase III detects cytosolic DNA and induces type I interferons through the RIG-I pathway. Cell 2009;138:576-591.

10. Sironi M, Peri AM, Cagliani R, et al. TLR3 mutations in adult patients with herpes simplex virus and varicella-zoster virus encephalitis. J Infect Dis 2017;215:1430-1434.

11. Bernard G, Chouery E, Putorti ML, et al. Mutations of POLR3A encoding a catalytic subunit of RNA polymerase Pol III cause a recessive hypomyelinating leukodystrophy. Am J Hum Genet 2011;89:415-423.

12. Tetreault M, Choquet K, Orcesi S, et al. Recessive mutations in POLR3B, encoding the second largest subunit of Pol III, cause a rare hypomyelinating leukodystrophy. Am J Hum Genet 2011;89:652-655.

13. Nagel MA, Forghani B, Mahalingam R, et al. The value of detecting anti-VZV IgG antibody in CSF to diagnose VZV vasculopathy. Neurology 2007;68:1069-1073. 


\title{
Neurology \\ Neuroimmunology \& Neuroinflammation
}

\author{
Varicella-zoster virus CNS vasculitis and RNA polymerase III gene mutation in \\ identical twins \\ Madalina E. Carter-Timofte, Anders F. Hansen, Maibritt Mardahl, et al. \\ Neurol Neuroimmunol Neuroinflamm 2018;5; \\ DOI 10.1212/NXI.0000000000000500
}

This information is current as of September 7, 2018

Neurol Neuroimmunol Neuroinflamm is an official journal of the American Academy of Neurology.

Published since April 2014, it is an open-access, online-only, continuous publication journal. Copyright

Copyright (C) 2018 The Author(s). Published by Wolters Kluwer Health, Inc. on behalf of the American

Academy of Neurology.. All rights reserved. Online ISSN: 2332-7812.

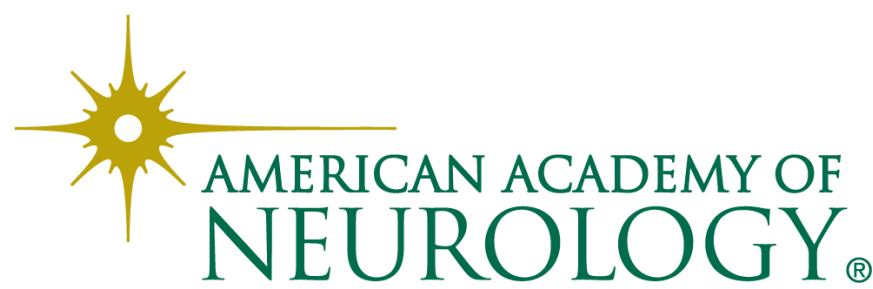




\section{Updated Information \& Services}

References

Citations

Subspecialty Collections

Permissions \& Licensing

Reprints including high resolution figures, can be found at: http://nn.neurology.org/content/5/6/e500.full.html

This article cites 13 articles, 0 of which you can access for free at: http://nn.neurology.org/content/5/6/e500.full.html\#\#ref-list-1

This article has been cited by 5 HighWire-hosted articles: http://nn.neurology.org/content/5/6/e500.full.html\#\#otherarticles

This article, along with others on similar topics, appears in the following collection(s):

\section{All Cerebrovascular disease/Stroke}

http://nn.neurology.org//cgi/collection/all_cerebrovascular_disease_str oke

All Genetics

http://nn.neurology.org//cgi/collection/all_genetics

Encephalitis

http://nn.neurology.org//cgi/collection/encephalitis

Vasculitis

http://nn.neurology.org//cgi/collection/vasculitis

Viral infections

http://nn.neurology.org//cgi/collection/viral_infections

Information about reproducing this article in parts (figures,tables) or in its entirety can be found online at:

http://nn.neurology.org/misc/about.xhtml\#permissions

Information about ordering reprints can be found online:

http://nn.neurology.org/misc/addir.xhtml\#reprintsus

Neurol Neuroimmunol Neuroinflamm is an official journal of the American Academy of Neurology.

Published since April 2014, it is an open-access, online-only, continuous publication journal. Copyright

Copyright $\odot 2018$ The Author(s). Published by Wolters Kluwer Health, Inc. on behalf of the American

Academy of Neurology.. All rights reserved. Online ISSN: 2332-7812.

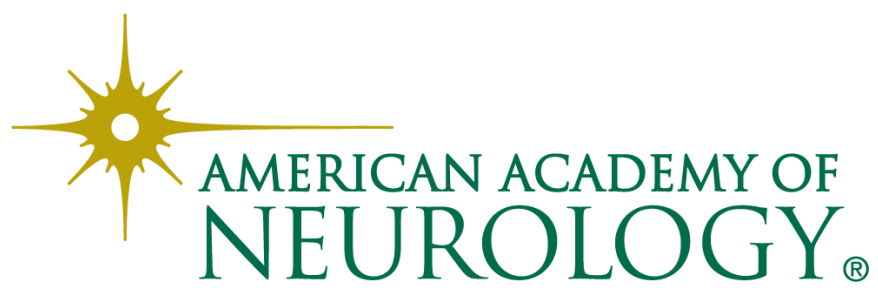

